\title{
Qualidade de frutos de tomate da cv. Santa Clara, mutante de fruto amarelo e seus híbridos $\mathbf{F}_{1}$.
}

\author{
Elizanilda R. do Rêgo'; Fernando L. Finger²; Vicente W. D. Casali \\ ${ }^{1}$ Universidade Federal de Roraima, Escola Agrotécnica, Campus do Paricarana, 69310 - 270, Boa Vista-RR; ${ }^{2}$ UFV - Depto. de \\ Fitotecnia, 36571-000, Viçosa - MG.
}

\begin{abstract}
RESUMO
A caracterização de alguns atributos físicos e químicos de frutos de tomate da cv. Santa Clara, um mutante de fruto amarelo, e o híbrido $\mathrm{F}_{1}$ obtido do cruzamento entre eles, foi feita com base nos teores de $\beta$-caroteno, licopeno, vitamina $\mathrm{C}, \mathrm{pH}$, matéria fresca, matéria seca, diâmetro do fruto, diâmetro do pericarpo, acidez e sólidos solúveis totais dos tecidos loculares e do pericarpo. Os frutos maduros amarelos apresentaram teores reduzidos de $\beta$-caroteno, licopeno e vitamina $\mathrm{C}$, enquanto o híbrido apresentou teores semelhantes ao genótipo normal. Tanto o fruto mutante quanto o $\mathrm{F}_{1}$ apresentaram teor de $\mathrm{pH}$ menor que o do fruto normal. Não houve diferença significativa quanto a matéria fresca e seca totais, diâmetro do fruto e do pericarpo e acidez. Os teores de sólidos solúveis totais do pericarpo foram inferiores nos frutos do mutante amarelo e $\mathrm{F}_{1}$, em relação ao genótipo normal, enquanto os teores de sólidos solúveis totais da massa locular não diferiram, estatisticamente, entre os genótipos.
\end{abstract}

Palavras-chave: Lycopersicon esculentum, $\beta$-caroteno, licopeno, sólidos solúveis.

\begin{abstract}
Quality of tomato red fruit, cv. Santa Clara, its yellow mutant and respective $F_{1}$ hybrid.

The determination of some physical and chemical attributes of red fruits from tomato cv. Santa Clara, a yellow mutant and the $F_{1}$ hybrid, were based on b-carotene, lycopene, vitamin $\mathrm{C}, \mathrm{pH}$, fresh and dry weight matter, pericarp and fruit diameter, titrateable acidity and total soluble solids. Ripe fruits of the yellow mutant showed reduced levels of $\beta$-carotene, lycopene and vitamin $C$, while fruits of the $\mathrm{F}_{1}$ hybrid showed levels of carotenoid pigments and vitamin $\mathrm{C}$ similar to the red fruit. Both mutant and $\mathrm{F}_{1}$ ripe fruits showed lower $\mathrm{pH}$ levels than the red parentals. Total fresh fruit and dry weight matter, pericarp and fruit diameter, and acidity were similar in the three genotypes studied. The total soluble-solids content of the pericarp was lower in the mutant and $F_{1}$ fruits, whereas their concentration in the locule tissues was similar in all genotypes.
\end{abstract}

Keywords: Lycopersicon esculentum, $\beta$-carotene, lycopene, soluble solids.

\section{(Aceito para publicação em 22 de março de 1999)}

\begin{abstract}
A cultura do tomate constitui-se na olerícola de maior importância econômica, tanto no comércio internacional quanto nacional. Num levantamento, a FAO (1995) estimou que a produção mundial de frutos situa-se em torno de 67 milhões de toneladas por ano, sendo $60-65 \%$ da produção processada pela indústria alimentícia.

A demanda de aceitação do tomate fresco baseia-se no teores de sólidos solúveis, aroma, sabor e nas características como cor, forma, firmeza, tamanho do fruto e formato (Hobson \& Grierson, 1993). Esses critérios são dependentes, primeiramente da composição química do fruto, como teores e composição de açúcares solúveis e ácidos orgânicos, $\mathrm{pH}$ e conteúdo de vitaminas (Dalal et al., 1965). Padrões de qualidade para polpa e pasta de tomate são definidos em termos de conteúdo de sólidos solúveis, composta por açúcares livres e ácidos orgânicos que são determinantes do sabor desse fruto (Tigchelaar, 1986).
\end{abstract}

Neste século, o tomate cultivado (Lycopersicon esculentum) foi submetido a intenso melhoramento genético, o que resultou na obtenção de variedades mais produtivas, com melhor qualidade de frutos e plantas com maior resistência a fatores adversos do meio (Stevens \& Rick, 1986). Contudo, em anos mais recentes, a introdução de variabilidade genética, em tomate cultivado, tem sido realizada pelo cruzamento com mutantes naturais, por variações somaclonais identificadas em cultura de calos e pela engenharia genética (Evans et al.,1984; Gray et al., 1992). Mutantes que interferem com a cor do fruto como "beta carotene", "delta", "greenripe", "yellow flesh", "apricot" e "tangerine", apresentam frutos com diferentes níveis de carotenóides, quando maduros, resultando em grande diversidade de cores no fruto amadurecido (verde, amarelo, laranja, rosa e vermelho) (Jenkins \& Mackinney, 1955; Rick \& Butler, 1956). O estudo da herança dos carotenóides de linhagens amarela e tangerine mostra que os mutantes diferem da linhagem vermelha por um único gene recessivo (Jenkins \& Mackinney, 1955). O mesmo fato foi observado por Rêgo et al. (1999) entre a cv. Santa Clara de fruto vermelho e o mutante amarelo. A variação genética na cor dos frutos de tomate cultivado depende basicamente de dois genes não-alélicos: $R_{-} T_{-}$, vermelho; rrT_, amarelo; R_tt, tangerine. No caso de homozigose recessiva, para o gene R, o nível de licopeno é reduzido em 95\%, em relação ao genótipo normal (Rick \& Butler, 1956).

$\mathrm{O} \mathrm{pH}$, em tomates, varia com a cultivar, sendo que $\mathrm{pH}$ menor que 4,3 diminui riscos de germinação de esporos de Clostridium botulinum em produtos processados, e danos por Bacillus coagulans em tomates destinados ao processamento (Wolf et al., 1979).

Os níveis de vitamina $\mathrm{C}$ produzidos pelo gênero Lycopersicon variam entre 10-120 mg.100 g MF-1, enquanto níveis de $\beta$-caroteno (pró-vitamina $\mathrm{A}$ ), superior a $0,3 \mathrm{mg} \cdot \mathrm{g} \mathrm{MF}^{-1}$, sendo uma cultura 
promissora para atender às necessidades diárias de consumo por pessoa (Rock et al., 1992; Wills et al., 1998). Genes que aumentam o conteúdo de carotenóides podem aumentar a atividade da pró-vitamina A, como por exemplo, o gene "high pigment" (hp). Esse gene oferece, também, oportunidade de aumentar os níveis de vitamina $\mathrm{C}$ no tomate cultivado (Tigchelaar, 1986).

Na região produtora de hortaliças de Viçosa, em 1994, identificou-se uma planta de tomate, entre mais de 20.000 da cv. Santa Clara, cujos frutos apresentavam coloração amarela, quando maduros. Por conseguinte, desenvolveu-se este trabalho que teve como objetivo caracterizar os genótipos normal da cv. Santa Clara, mutante amarelo e sua geração $\mathrm{F}_{1}$, com base em características físicas e químicas do fruto.

\section{MATERIAL E MÉTODOS}

Plantas da cv. Santa Clara, dos genótipos normal e mutante amarelo, foram cultivadas em vaso, em casa de vegetação, para obtenção de sementes da geração $\mathrm{F}_{1}$, resultantes do cruzamento recíproco entre as cultivares Santa Clara normal e seu mutante amarelo. Cada vaso continha uma planta com uma haste, que recebeu adubação e tratos culturais normais à cultura.

Com o objetivo de caracterizar as plantas, por meio de análise nutricional de frutos, foi estabelecido um experimento de campo, utilizando-se o delineamento experimental blocos casualizados, com três tratamentos (genótipos normal, mutante e híbrido $\mathrm{F}_{1}$ ) em quatro repetições. Cada parcela foi constituída por 10 plantas úteis e a amostra de cada repetição foi composta de dois frutos maduros (63 dias após a antese), por parcela, totalizando oito frutos. A adubação e os tratos culturais foram realizados segundo os padrões para a cultura. Os resultados obtidos foram submetidos à análise de variância e as médias dos tratamentos comparadas pelo teste de Duncan, em 5\% de probabilidade. Para as análises estatísticas, usou-se o programa SAEG, desenvolvido pela Universidade Federal de Viçosa.

$\mathrm{Na}$ análise de licopeno e de $\beta$ caroteno, cerca de $20 \mathrm{~g}$ de pericarpo de

Tabela 1. Teores médios de $\beta$-caroteno e licopeno em frutos ${ }^{1}$ de tomates maduros da cv. Santa Clara, mutante amarelo e $\mathrm{F}_{1}$. Viçosa, UFV, 1996.

\begin{tabular}{lcc}
\hline \multirow{2}{*}{ Genótipos } & \multicolumn{2}{c}{ Teor $\left(\mathbf{m g ~ g ~ M F}^{1}\right)$} \\
\cline { 2 - 3 } & $\boldsymbol{\beta}$ - Caroteno & Licopeno \\
\hline Normal & $3,9 \mathrm{a}$ & $105,7 \mathrm{a}$ \\
Mutante & $0,9 \mathrm{~b}$ & $0,7 \mathrm{~b}$ \\
$\mathrm{~F}_{1}$ & $2,5 \mathrm{ab}$ & $81,7 \mathrm{a}$ \\
\hline
\end{tabular}

As médias seguidas de mesma letra na coluna não diferem entre si, pelo teste Duncan, em $5 \%$ de probabilidade.

${ }^{1}$ Frutos colhidos com 63 dias após a antese.

cada fruto foram homogeneizados em $20 \mathrm{~mL}$ de acetona e $60 \mathrm{~mL}$ de hexano $\left(65^{\circ} \mathrm{C}\right)$, em homogeinizador de tecidos Turrax. O homogeneizado foi filtrado em papel de filtro e levado a um funil de separação, sendo então lavado seqüencialmente com $20 \mathrm{~mL}$ das seguintes soluções: $90 \%$ de metanol, $20 \%$ de $\mathrm{KOH}, 90 \%$ de metanol e, finalmente, água, por $30 \mathrm{~min}$, para cada lavagem. A fase inferior do extrato foi descartada e a solução contendo hexano foi analisada em espectrofotômetro, Hitachi U2000, nos comprimentos de 487,5 nm e $502 \mathrm{~nm}$, onde se determinavam carotenóides totais e licopeno, respectivamente (Zscheile \& Porter, 1947).

$\mathrm{O} \mathrm{pH}$ e o teor de vitamina $\mathrm{C}$ foram analisados em cerca de $10 \mathrm{~g}$ de tecido (pericarpo e tecido locular), adicionandose $100 \mathrm{~mL}$ de água destilada que foram homogeneizados em homogeinizador de tecidos Turrax. O homogeneizado foi levado a um potenciômetro para determinação do pH. Após a determinação do pH, adicionou-se ao homogeneizado $10 \mathrm{~mL}$ de ácido sulfúrico a 20\%, $1 \mathrm{~mL}$ de iodeto de potássio a $10 \%$, e $1 \mathrm{~mL}$ de solução de amido a $1 \%$, e titulou-se com iodato de potássio $0,01 \mathrm{~N}$, de acordo com método descrito pelo Instituto Adolfo Lutz (1985).

Frutos maduros provenientes dos três primeiros cachos foram pesados $\mathrm{e}$ cada fruto foi cortado na região equatorial e retiradas duas medidas referentes ao diâmetro do fruto e quatro relacionadas ao pericarpo, com o auxílio de um paquímetro. Após, os frutos foram secados em estufa de ventilação forçada, a $65^{\circ} \mathrm{C}$, até a obtenção de peso constante para estimativa de matéria seca total.

Para análise de sólidos solúveis totais, cerca de $10 \mathrm{~g}$ de cada tecido, pericarpo ou do tecido locular, foram macerados em almofariz com auxílio de um pistilo. Retiraram-se $50 \mathrm{~mL}$ do macerado, que foi levado a um refratômetro do tipo Abbé. Para a determinação da acidez titulável, cerca de $10 \mathrm{~g}$ de polpa ou pericarpo foram macerados em homogeneizador Turrax com $100 \mathrm{~mL}$ de água destilada. Ao homogeneizado foram acrescentadas três gotas de fenoftaleína a $1 \%$ e procedeu-se à titulação com $0,1 \mathrm{~N}$ de $\mathrm{NaOH}$. Os resultados foram expressos em porcentagem de ácido cítrico.

\section{RESULTADOS E DISCUSSÃO}

Houve diferenças significativas, entre genótipos, quanto aos caracteres $\beta$ caroteno e licopeno, em $5 \%$ de probabilidade (Tabela 1). Tanto $\beta$-caroteno quanto licopeno estão presentes em quantidades mínimas nos tomates mutantes, enquanto os frutos híbridos possuem teores de $\beta$-caroteno semelhantes aos normais e do mutante amarelo, e concentração de licopeno similar ao tomate normal (Tabela 1 ). $O$ teor de $\beta$ caroteno do fruto híbrido não diferiu estatisticamente dos pais, o que indica uma interação, do tipo dominância parcial, entre os alelos que controlam o conteúdo desse pigmento. Dados semelhantes foram encontrados por Lincoln \& Porter (1950), trabalhando com espécies de tomate com fruto laranja e vermelho. Os autores concluíram que a herança do teor de $\beta$-caroteno é monogênica (gene B) com dominância parcial, nessas espécies.

Os frutos normais e seus híbridos $\mathrm{F}_{1}$ não diferiram, estatisticamente, em relação ao teor de licopeno (Tabela 1). O tomate amarelo apresentou redução nos teores de $\beta$-caroteno e licopeno, de 77,0 
Tabela 2. Teores médios de vitamina $\mathrm{C}$ e $\mathrm{pH}$ em frutos $^{1}$ de tomates maduros do cv. Santa Clara, mutante amarelo e $\mathrm{F}_{1}$. Viçosa, UFV, 1996.

\begin{tabular}{lcc}
\hline \multicolumn{1}{c}{ Genótipos } & Vitamina C (mg $100 \mathbf{g ~ M F}-1)$ & pH \\
\hline Normal & $6,7 \mathrm{ab}$ & $4,4 \mathrm{a}$ \\
Mutante & $4,5 \mathrm{~b}$ & $4,3 \mathrm{~b}$ \\
F1 & $7,8 \mathrm{a}$ & $4,3 \mathrm{~b}$ \\
\hline
\end{tabular}

As médias seguidas de mesma letra na coluna não diferem entre si pelo teste Duncan, em $5 \%$ de probabilidade.

${ }^{1}$ Frutos colhidos com 63 dias após a antese.

Tabela 3. Totais de sólidos solúveis do tecido locular (TSSTL) e do pericarpo (TSSPE), acidez do tecido locular (ATL) e do pericarpo (APE), matéria fresca (MF) e seca (MS), diâmetro (DIAF) e do pericarpo (DIAPE) em frutos ${ }^{1}$ de tomate da cv. Santa Clara normal, mutante amarelo e seus híbridos $\mathrm{F}_{1}$. Viçosa, UFV, 1996.

\begin{tabular}{lrrr}
\hline Características & Normal & Mutante & \multicolumn{1}{c}{$\mathbf{F}_{1}$} \\
\hline TSSTL (\%) & $4,15 \mathrm{a}$ & $3,97 \mathrm{a}$ & $3,75 \mathrm{a}$ \\
TSSPE (\%) & $4,00 \mathrm{a}$ & $3,81 \mathrm{~b}$ & $3,83 \mathrm{~b}$ \\
ATL (\%) & $0,34 \mathrm{a}$ & $0,33 \mathrm{a}$ & $0,30 \mathrm{a}$ \\
APE (\%) & $0,25 \mathrm{a}$ & $0,21 \mathrm{a}$ & $0,22 \mathrm{a}$ \\
MF (g) & $190,37 \mathrm{a}$ & $203,79 \mathrm{a}$ & $202,21 \mathrm{a}$ \\
MS (\%) & $6,27 \mathrm{a}$ & $6,19 \mathrm{a}$ & $6,17 \mathrm{a}$ \\
DIAF (mm) & $66,50 \mathrm{a}$ & $67,20 \mathrm{a}$ & $65,50 \mathrm{a}$ \\
DIAPE (mm) & $6,38 \mathrm{a}$ & $6,03 \mathrm{a}$ & $6,13 \mathrm{a}$ \\
\hline
\end{tabular}

As médias seguidas de mesma letra na linha não diferem entre si pelo teste Duncan, em 5\% de probabilidade.

${ }^{1}$ Frutos colhidos com 63 dias após a antese.

e 99,3\%, respectivamente, em relação aos teores encontrados nos frutos da cultivar normal. Esses dados diferem dos obtidos por (Jenkins \& MacKinney, 1955), que concluíram que o gene $\mathbf{r}$ em homozigose reduzia os níveis de licopeno do fruto para 5\%, em relação ao genótipo $\mathbf{R R}$.

O licopeno é o pigmento vermelho dos tomates maduros, enquanto que no mutante amarelo, em razão de um bloqueio genético no processo de maturação, não há a formação desse pigmento. No entanto, ocorre complementação gênica quando se obtêm os híbridos $\mathrm{F}_{1}$, entre as plantas normal e mutante, sendo restaurada a síntese de licopeno (Tabela 1).

Houve diferença significativa, entre os genótipos, para as características vitamina $\mathrm{C}$ e $\mathrm{pH}$, em $5 \%$ de probabilidade (Tabela 2). Os frutos mutantes apresentaram redução nos teores de vitamina $\mathrm{C}$ de $32,8 \%$, em relação aos do genótipo normal, enquanto que para o híbrido não houve diferença estatística em relação ao fruto normal (Tabela 2).
Os valores de $\mathrm{pH}$, tanto do mutante quanto do $\mathrm{F}_{1}$, apresentaram redução de cerca de $3 \%$, quando comparados com frutos do genótipo normal (Tabela 2). Os dados de $\mathrm{pH}$, encontrados neste trabalho, são semelhantes aos obtidos por Wolf et al. (1979), trabalhando com variedades de tomate de fruto amarelo. Conforme Rice \& Pederson (1954), o $\mathrm{pH}$ ideal de produtos processados deve ser menor ou igual a 4,3, para diminuir riscos de danos causados por Bacillus coagulans. Partindo deste pressuposto, o mutante amarelo pode ser usado em programas de melhoramento que visem diminuir o $\mathrm{pH}$ dos frutos destinados ao processamento, uma vez que o híbrido tem o mesmo pH do mutante, além de apresentar coloração vermelha, desejável em tomates destinados tanto para consumo a fresco como para processamento.

Os teores de sólidos solúveis totais do pericarpo foram menores no mutante e $\mathrm{F}_{1}$, em relação ao genótipo normal (Tabela 3). O menor teor de sólidos solúveis é uma característica indesejável, para fins de melhoramento de produtos processados, porém não houve diferença significativa, entre os genótipos quanto ao teor de sólidos solúveis totais do tecido locular (Tabela 3). Também, não houve diferença significativa, em 5\% de probabilidade quanto à acidez do tecido locular e pericarpo, matéria fresca e seca do fruto e diâmetro do fruto e do pericarpo (Tabela 3). As semelhanças entre os genótipos quanto a estas características permite a recuperação do genótipo recorrente em menor espaço de tempo. Segundo Allard (1971), o melhoramento genético por mutação parece ser especialmente útil na troca de características que têm uma herança simples, enquanto o melhoramento por hibridação pode levar ao rompimento de uma combinação gênica superior.

Em outros mutantes como o $h p, o g^{c} \mathrm{e}$ $d g$, que aumentam a quantidade de vitamina $\mathrm{A}$ e $\mathrm{C}$, as plantas são menos vigorosas que as plantas normais (Wann \& Jourdain, 1985). Também os mutantes Nor e rin, apesar de produzirem frutos com maior retenção da firmeza, possuem menor teor de $\beta$-caroteno (Sink et al., 1974) e de ácido ascórbico (Gonzalez \& Brecht, 1978) e muitos de seus híbridos não atendem às exigências organolépticas para mesa (Zambon, 1984). Em ensaios de campo, as plantas do mutante de frutos amarelos apresentaram o mesmo vigor das plantas normais, inclusive nos primeiros estágios de desenvolvimento (dados não apresentados).

\section{AGRADECIMENTOS}

Ao Professor Antônio Américo Cardoso, Depto. de Fitotecnia/UFV, pela colaboração nas análises estatísticas e ao $\mathrm{CNPq}$ pela concessão de bolsa de mestrado.

\section{LITERATURA CITADA}

ALLARD, R. W. Princípios do melhoramento genético, Rio de Janeiro: USAID, 1971, 381 p.

BASSET, M. J. Breeding vegetables crop. Westport: AVI Publishing, 1986. 584 p.

DALAL, K. B.; SALUNKHE, D. K.; BOE, A. A.; OLSON, L. E. Certain physiological and biochemical changes in the developing tomato fruit (Lycopersicon esculentum). Journal of Food Science, v. 30, p. 504-508, 1965. 
EVANS, D. A.; SHARP, W. R.; MEDINA FILHO, H. P. Somaclonal and gametoclonal variation. American Journal of Botany, v. 71, p. 759-774, 1984.

FAO. Production yearbook for 1994. Rome: FAO, v. $48,1995$.

GONZALEZ, A. R.; BRECHT, P. E. Total and reduced ascorbic acid levels in rin and normal tomatoes. Journal of the American Society for Horticultural Science, v. 103, n. 6, p. 756-758, 1978.

GRAY, J. E; PICTON, S.; SHABBER, J.; SCHUCH, W.; GRIERSON, D. Molecular biology of fruit ripening and its manipulation with antisense genes. Plant Molecular Biology, v. 19 , p. $69-87,1992$.

INSTITUTO ADOLFO LUTZ Normas Analíticas do Instituto Adolfo Lutz, 3. ed. São Paulo: Ed. Adolfo Lutz, v.1, 1985. 375 p.

JENKINS, J. A.; MACKINNEY, G. Carotenoids of the apricot tomato and its hybrids with yellow and tangerine, Genetics, v. 40, p. 715720, 1955.

LINCOLN, R. E., PORTER, J. W. Inheritance of Beta-Carotene in tomatoes. Genetics, v. 35, p. 206-211, 1950.

RÊGO, E. R.; FINGER, F. L.; CASALI, V. W. D.; CARDOSO, A. A. Inheritance of fruit color and pigment changes in a yellow tomato (Lycopersicon esculentum Mill.) mutant. Genetics and Molecular Biology, v. 22, n. 1, 1999. (in press)
RICE, A. C.; PEDERSON, C. S. Factors influencing growth of Bacillus coagulans in canned tomato juice. Food Research, v. 19, p. 124, 1954.

RICK, C. M.; BUTLER, L. Cytogenetics of the tomato. Advances in Genetics, v. 8, p. 267-382, 1956.

ROCK, C. L. ; SWENDSEIDE, D. M. E.; JACOB, R. A.; McKEE, R. W. Plasma carotenoid levels in human subjects fed a low carotenoid diet. Human Clinical Nutrition, v. 122, p. 96-100, 1992.

SINK, K. C.; HERNER, R. C.; KNOWLTON, L. L. Chlorophyll and carotenoid of the rin tomato mutant. Canadian Journal o Botany. v. 52, p. 1657-1659, 1974.

STEVENS, M. A.; RICK, C. M. Genetics and breeding. In: ATHERTON, J. G., RUDICH, J. (Eds.) The tomato crop, London: Chapman \& Hall, 1986. p. 35-109.

TIGCHELAAR, E. C. Tomato breeding. In BASSET, M. J. Breeding vegetables crop. Westport: AVI Publishing, 1986. p. 135-166.

WANN, E. V.; JOURDAIN, E. L. Effect of mutant genotypes $\mathrm{hp} \mathrm{og}^{\mathrm{c}}$ and $\mathrm{dg} \mathrm{og}^{\mathrm{c}}$ on tomato fruit quality. Journal of the American Society for Horticultural Science, v. 110, p. 212-215, 1985.
WILLS, R.; McGLASSON, B.; GRAHAM, D.; JOYCE, D. Postharvest and introduction to physiology and handling. $4^{\text {th }}$. Wallingford: CAB International, 1998. 262 p.

WOLF, I. D.; SCHWARTAU, C. M.; THOMPSON, D. R.; ZOTTOLA, E. A.; DAVIS, D. W. The pH of 107 varieties of Minessota-grown tomatoes. Journal of Food Science, v. 44, p. 1008-1010, 1979.

ZAMBON, F.R.A. Comparação dos processos de maturação de tomate (Lycopersicon esculentum, Mill.) KADA, Mutantes NOR e RIN e seus híbridos $F_{l}$. Viçosa: UFV, 1984. 45 p. (Tese mestrado)

ZSCHEILE, F. P.; PORTER, J. W. Analytical methods for carotenes of Lycopersicon species and strains. Analytical Chemistry, v. 19, n. 1, p. 47-51, 1947. 